DOI: 10.2478/pcssr-2018-0021

\title{
Karate: Emotions and Movement Anticipation
}

Authors' contribution:

A) conception and design of the study

B) acquisition of data

C) analysis and interpretation of data

D) manuscript preparation

E) obtaining funding
Danilo Contiero $^{1 \mathrm{~A}-\mathrm{C}}$, Jerzy Kosiewicz ${ }^{2 \mathrm{~A}-\mathrm{C}}$, Julien S. Baker ${ }^{1 \mathrm{~A}-\mathrm{C}}$

${ }^{1}$ School of Health and Life Sciences, University of the West of Scotland, ${ }^{2}$ Josef Pilsudski University of Physical Education in Warsaw, Poland

ABSTRACT

\section{Introduction}

The following paper is a case study developed to investigate the possible relationship between mirror neurons and karate.

In karate, athletes are often trained to anticipate the opponent's movement and to consider their emotions (Dosil 2006). This kind of training and skill may be linked to the concept related to mirror neurons, which are connected to the identification of the intention behind an action and are involved in a sort of automatic empathy of "really feeling what another person is feeling or going to do" (Carey 2006).

\section{Methods}

The research is an introductive literary review about martial arts and the theory of mirror neurons and provides a case study based on interviews.

Participants have been asked to answer five questions related to the topic. All of them are expert athletes at the black belt level or with at least 10 years of training experience.

KEYWORDS

karate, emotions, movement anticipation

\section{Introduction}

The following paper is a case study developed to investigate the possible relationship between mirror neurons and karate.

In karate, athletes are often trained to anticipate the opponent's movement and to consider their emotions (Dosil 2006). This kind of training and skill may be linked to the concept related to mirror neurons, which are connected to the identification of the intention behind an action and are involved in a sort of automatic empathy of "really feeling what another person is feeling or going to do" (Carey 2006).

\section{Methods}

The research is an introductive literary review about martial arts and the theory of mirror neurons and provides a case study based on interviews.

Participants have been asked to answer five questions related to the topic. All of them are expert athletes at the black belt level or with at least 10 years of training experience. 


\section{Results}

The research provides new information relating to karate, which embraces a complex mentalistic activity and shows that martial artists are continuously focused and able to anticipate actions/situations of the opponent and to empathize with the "enemy."

It is not clear if this ability is dependent on mirror neurons, but it is definitely a binomial that requires further research.

\section{The Case}

The paper has been inspired by focusing the attention on sparring between athletes who practice martial arts. The authors noticed that during the fights, some expert athletes were able to anticipate the actions and movements of their opponents. The anticipation of the actions seemed to be linked to a kind of emotional connection with the opponent (Dosil 2006). This has inspired the hypothesis that when the athlete is able to feel the emotions of the enemy, such as anger or fear, their method for managing the fight changes, making the competitor feel more confident or more prudent when choosing their technique and strategy.

The authors noted also that in competitions, experts change their behavior in the fight to induce a preferred "state of mind" in the opponent that will help them manage the situation. For example, when highlevel athletes compete for a final match, a stall occurs at the beginning. Both of the athletes are very good, and this is why they are matched for the final. Attacking first may be a risk. Some experts demonstrate that in this phase of activity, to be enticed or annoyed by the situation causes them to drop their guard and sometimes encourages the opponent to attack. A good example can be observed in the final match for the 2014 World Karate Championships between Rafael Aghayev and Luigi Busa, where both athletes, who were world champions, waited to attack and received the "Chukoku" penalty. This apparently harmless behavior is forbidden in official competitions, as is reported by the Italian Federation of Judo, Karate, and Martial Arts (FIJLKAM) in "Article 8: Forbidden Behaviors" (FIJLKAM 2008), contained in the document "Regolamento d'arbitraggio per le competizioni di Karate" (Arbitrage rules for karate competitions). Indeed, most times this strategy is just a falsehood that makes the opponent confident to attack, but the attack has been induced, planned, and is anticipated. After an informal and easy investigation, the authors found that the same perception was shared by other expert athletes, although it was a less common view among beginners. The perception found a solid basis in the theory of mirror neurons and their link with emotions.

This finding led the authors to investigate whether the skill of movement anticipation, as empathy or the induction of emotion, is related to mirror neuron activity.

This research provides a new perspective on karate and martial arts, presented not as a sport of only strength and violence, but also as one focused on training for technique and a mentalistic investigation of others.

\section{The background: Mirror neurons}

Mirror neurons were discovered about 20 years ago in the monkey brain, and there is now evidence, according to some researchers, that they are also present in the human brain (Cook et al. 2014; Mukamel et al. 2010).

Mirror neurons are motor neurons that show signs of activity not only when a person moves, but also when a person only observes someone else making a movement, or observes the intention behind the action (Carey 2006; Keysers et al. 2010).

Most researchers almost dogmatically associate mirror neurons with the following brain regions: the ventral premotor (vPM) cortex, the inferior parietal lobule (IPL), the supplementary motor area, and the primary somatosensory cortex (Keysers et al. 2010; Molenberghs et al. 2009).

It is very common to hear phrases such as "I felt in in my gut" or "I was sure it was going to happen." According to recent research, the ability to anticipate actions and feelings can be explained by the actions of mirror neurons.

Mirror neurons are not only involved in the motor system, but are also related to feelings and emotions. 
Dapretto, a researcher at the UCLA Brain Research Institute, suggests that the mirror neuron system seems to be involved in a sort of automatic empathy of "really feeling what another person is feeling or going to do" (Carey 2006).

Social psychology demonstrates that imitation and mimicry are pervasive, automatic, and facilitate empathy.

In neuroscience, with the discovery of mirror neurons, it has become possible to understand how we can access and understand the minds of other people (Iacoboni 2009).

A large number of experiments using MRI, electroencephalography (EEG), and magnetoencephalography (MEG) have shown that some brain regions (in particular the anterior insula, anterior cingulate cortex, and inferior frontal cortex) are active when people experience an emotion (disgust, happiness, pain, etc.) and when they see another person experiencing an emotion (Botvinick et al. 2005; Cheng et al. 2008).

People who are more empathetic have stronger activations both in the mirror system for hand actions and in the mirror system for emotions. This means that these individuals are more likely to be able to forecast actions and empathize with the feelings of people they relate to (Gazzola et al. 2006; Jabbi et al. 2007).

Studies suggest that mirror neuron activity is positively correlated with psychotic symptoms. Higher mirror neuron activity may be the underpinning of schizophrenia and may contribute to sensory misattributions, particularly in response to socially relevant stimuli, and may be a putative mechanism for delusions and hallucinations (McCormick et al. 2012).

The goal of the study is to understand if it is possible that individuals who have trained in martial arts or sports where it is necessary to relate to an opponent, and as a result potentially understand their opponent's intentions and actions, can improve the activity of the mirror neurons, which could result in empathy with the opponent.

Do professional martial arts champions have enhanced empathy and better action anticipation than less successful athletes?

\section{Martial arts, empathy, and the anticipation of action}

Martial arts have captivated society for many years. There are 50 million karate practitioners worldwide ("Martial Arts: Fact Sheet" 2015). According to the South Korean government, there were 70 million people practicing taekwondo in 190 countries in 2009 (Kim 2009).

The term "martial arts" alludes to those codified practices and traditions whose goal is to submit or selfdefend through technique. There are several styles and schools of martial arts. What differentiates martial arts from mere bellicose or physical violence (street fights) is the organization of their techniques and tactics into a coherent system, adherence to a philosophy of life or code of conduct, and the coding of effective methods tested in antiquity (Jimenez 2017).

Martial arts have a very strong link with religion and empathy. According to tradition, martial arts were founded around 520 A.D. by Bodhidharma, a great Buddha who brought Zen Buddhism from India to China. He meditated and experienced the revelation that he should study animals. So he began to do so, and from this study he eventually developed the "Eighteen Movements of Lo Han." (Reid et al. 1983; Kopel 2017). After meeting with Shaolin monks in China, he developed these forms into kung-fu (Kopel 2011).

When China was ruled by the Mongols, the prohibition of arms for the subjugated Chinese population was so severe that only 1 out of 10 families was allowed a carving knife. Martial arts were the only way people could defend themselves and their culture (Kopel 2011).

For example, when Japan conquered Okinawa in 1609 and disarmed the island's people, the Okinawans practiced martial arts as a means of preserving their cultural identity (Kopel 2011).

One of the essential goals of spiritual growth through martial arts is to forget oneself, a kind of meditation in movement.

The mind must always be in the state of "flowing." As is quoted in Joe Hyam's Zen in the Martial Arts (1982, p. 84): 
When the swordsman stands against his opponent, he is not to think of the opponent, nor of himself, nor of his enemy's sword movements, he just stands there with his sword which, forgetful of all technique, is ready only to follow the dictates of the unconscious. The man has effaced himself as the wielder of the sword. When he strikes, it is not the man but the sword in the hand of the unconscious that strikes.

Independent of history and background, martial arts are very popular in modern society. Judo is already an Olympic sport, and karate is set to become one in 2020.

It has been discovered that among people who practice martial arts as a sport, the best competitors have higher self-esteem and sports confidence (Richman et al. 1986). Self-confidence can be defined as "the belief that you can successfully perform a desired behaviour" (Weinberg et al. 1999).

Individuals who practice martial arts are continuously exposed to stressful situations in training, fights, and sparring. These situations are never the same, as the opponent or the strategy is always changing. Therefore, one's coping skills are constantly improving, and the ability to control one's emotions is continually evolving (Howell 2003).

Empathy is one of the skills that martial artists gain as part of their training experience. Being able to understand how a person is feeling and how to act appropriately according to those feelings is essential (Howell 2003).

In the study of S.Twemlow in 2008, it was demonstrated that martial arts training has been able to decrease bullying in the school environment by teaching children empathy, self-control, and peaceful strategies for resolving conflicts (Twemlow et al. 2008).

Most training in martial arts is focused on the anticipation of an attack from an opponent. Action anticipation plays an important role in the successful performance of open skill sports such as combat sports. Evidence from a study by Shih et al. (2016) has shown that elite athletes from open sports excel in action anticipation. The results suggest that the recognition of facial emotions plays a determinant role in the prediction of action in combat sports such as taekwondo (Shih et al. 2016).

Martial artists are able to quickly evaluate an opponent's body mechanics and movements (Heidelberg 2016).

\section{Methods}

The introduction of the paper is based on a literary review about mirror neurons and martial arts. Most of the papers that have been included in this review were identified online using different scientifically relevant search engines, such as PubMed. Others, mostly involving the history of martial arts, have been selected from well-known literature related to scientific interview methodologies. No studies have been published involving the topic of mirror neurons and martial arts or the anticipation of movement and empathy. This has limited the research to include only a small number of papers from the original hundreds, a selection that now consists of 22 papers.

The interview has been selected as the methodology to investigate the topic in this qualitative pilot study. Karate experts from two different countries, styles, and training protocols were asked questions relating to the topic of martial arts, empathy, and mirror neurons. The authors have considered athletes with a black belt or with at least 10 years of training and competitive experience to be experts.

Before beginning the interview, the subjects were asked to agree or disagree with the idea that mirror neurons show signs of activity not only when a person moves, but also when a person observes someone else making a movement, so that they seem to be involved in a sort of automatic empathy of "really feeling what another person is feeling" (Carey 2006). Empathy is the "capacity" to share and understand another's "state of mind" or emotion (Ioannidou et al. 2008), with the understanding that stress is anything that seriously threatens human homeostasis (Schneiderman et al. 2005).

The interview was based on a simple questionnaire containing 5 open questions:

1. Do you agree with the previous definitions of mirror neurons, empathy, and stress? 
2. According to the study of Howell in 2003, people who practice martial arts are continuously exposed to stressful situations when training, improving their coping skills and learning to control their emotions. Do you agree? If so, why?

3. Do you notice a higher level of emotional control and ability to empathize in expert martial arts athletes? If yes, could you provide an example?

4. Do you practice, in your martial art, exercises that aim to anticipate the attack of the opponent? (Feel free to provide examples.) Does training lead to improvements? Do you think it is just an anticipation of the movement/technique or also an ability to feel/read emotions? Do you note a difference in this skill between experienced and less experienced athletes?

5. How much importance do you think the ability to anticipate the technique and feel the emotion of the adversary is when you fight in the Dojo or in a competition?

The participants were asked to write their answers and send them back to the authors by email; they were also asked if they would allow their personal and professional data to be published. Only the first interview, with Participant \#1, was recorded with a common audiotape recorder and sent to the authors. This was kept in a secure location with other transcripts and access is available only to the authors.

\section{Interviews}

\section{Participant no 1}

"Reading the intention"

A $7^{\text {th }}$ dan karate master, ex-president of the youth national Italian team of karate, National Counsellor of the Italian Karate Federation (FIJLKAM), and a highly decorated athlete in Italian, European, and World Championship competitions, gives his answers to the questionnaire:

\section{Yes!}

2. Yes, in karate stress is procured not only by a continuous change of fighting situations, but also by a continuous change of opponents, leading the athlete to engage in continuous adaptation, striving to find a solution to a new and different problem every time. In these situations, it is necessary to try to identify yourself in the adversary and try to understand what he is feeling, improving the exercise of empathy.

3. Empathy is prime in martial arts, even in the relationship between coach and athlete, and needs very precise rules. For example, the empathy between the technician and the athlete is a relationship that can be dangerous. Empathy must not become sympathy; the technician must not load the athlete's emotions, but rather must maintain a certain detachment. On the other hand, in combat empathy is much more often experienced among experts and is used by athletes to induce a known behavior in the opponent through technical gesture and tactics. Basically, the experienced athlete tries to put the opponent in a situation that he is familiar with and in which he knows what he feels. This allows him to anticipate not so much the technical gesture but the emotive action/reaction of the opponent.

4. The anticipation is a reading of the body and feelings. Usually it is trained with preordained exercises, but this also depends on the experience of the athlete and his or her ability to observe, read, and memorize the different motor skills and techniques, creating a sort of database that then provides the possibility to read the various situations and anticipate them. The goal of anticipation, however, is not the anticipation of technique; the true goal is the anticipation of the opponent's situation and intention. Technique is the means that the athlete uses to express his intention, and anticipating the technique means having first anticipated the intention. The skill of the expert athlete is to create the situations and emotions that he needs in order to be victorious; for example, causing anger in the opponent in order to push him to attack just when the athlete wants him to attack. To do this, it is necessary to learn to feel what other people feel. To create empathy between you and the opponent, it is necessary to have an excellent proprioception of the body. Proprioception is more developed in expert athletes. In fact, sometimes novices tend to focus on their movements, rather than trying to understand the opponent's movement and emotions, because they are not yet confident. 
5. The ability to understand, feel and anticipate emotions and situations is the soul of combat. Combat in martial arts goes beyond the execution of techniques; it is the interaction and reading of bodies and emotions. I think that empathy is a characteristic of karate and all martial arts, and I think it is a cornerstone for the growth of the athlete and the person.

\section{Participant no 2}

"Emotional suspension"

The second interview was answered by a $2^{\text {nd }}$ dan black belt athlete and trainer, also a member of the National Italian Council for Master Karate Athletes (FIJLKAM).

1. As far as I know, one can think of mirror neurons as the structure, and empathy as a function. To give a simple example, think of a guitar (mirror neurons) and the music it produces (function, empathy). The bibliography and theories on what empathy is are vast, and even today we ask ourselves what it is exactly, or how we should describe it. Very often, for example, empathy is confused with "sympathy," the ability to "put oneself in the other's place," to feel what the other feels. Well, empathy is something more, both quantitatively and qualitatively. Empathy is that human capacity (which not all humans possess and exercise in the same way) that allows us to be in communication with the other and to respond to the communicative stimuli received in an appropriate and coherent manner.

To return to the example of the guitar, sympathy is when two instruments vibrate on the same string, while empathy is when one of the instruments vibrates on a certain string and the other instrument understands which string the first instrument is vibrating on.

2. About the first point, I believe that the practice of martial arts is a very powerful means to learn both to control one's emotions and to know another empathetically, but both of these skills are not automatic, especially with regard to emotional control. For example, in sparring, while you continually experience how to stay in combat with each other, with regard to the control of emotions, there is a need for a "mentalization" that takes place through someone who provides us with stimuli from the outside (usually this is the Master). In many Dojos, the stimuli aiming to control emotions are not the focus of training, and therefore this learning does not take place. Many practitioners, even experts, struggle to even feel and properly recognize their psychophysical state, that is, the basic body signals that indicate that an "emotional state" is taking place. It is clear, therefore, that if one is not able to feel an emotional state, the next steps of cataloguing the emotional state are impossible, as is learning to control it.

Regarding the second point of the question, related to stress, I absolutely agree. Martial arts practitioners are used to and trained to experience high levels of stress.

3. In my experience, I have often noticed that more experienced athletes, more than the control of emotions, are able to enter a psychophysical state that I would almost call "emotional suspension," a sort of emotional stand-by, waiting for something that is to come or that "should" take place.

This is strongly linked, in my opinion, to the empathic processes. Let me explain better: during a fight, there are some phases in which it is still unclear what will happen, and therefore being "suspended" allows for better adaptation to a suitable countermeasure when the event is realized (an attack, for example). This also occurs in the emotional sphere.

4.Yes, in the practice of sports karate, there are many exercises aimed at anticipating the opponent's intentions, and training this ability certainly leads to improvements. In my opinion, this training brings benefits not so much and not only regarding reflexes and the acquisition of familiarity with certain movements/actions, but also for the construction and expansion of a "database" of actions carried out by the opponent that we can then recognize when they occur as events. I emphasize that this "database" is unconscious; we have no awareness of it, but it is there. The differences between inexperienced and expert athletes are, in my opinion, a very fascinating aspect of this process. During sparring or a real fight, an inexperienced athlete will probably be very alert and will use innate schemes concerning attack and defense. To put it in simple terms, an inexperienced athlete will rely on his instincts and his mammalian genetic makeup. When one begins to learn a martial art, there is a period of time, which can subjectively feel more or less long, in which the technique pollutes and conditions instinct into automatic responses. After this period, the technique begins to be an ally 
in the service of instinct, and no longer an uncomfortable host. From what is known of mirror neurons, they are activated and function if they "recognize" something known in the other, so for inexperienced athletes these cannot be activated in front of an "opponent" who uses a set of technical movements that for the inexperienced recipient are "new." Obviously, speech is different for experienced athletes, who instead can use instinct in unison, leveraging the mirror neuron system and technique for their needs.

5. Anticipating an opponent in a combat sport, and therefore also in the practice of martial arts, is a major competitive advantage. Knowing how to anticipate an opponent means actually preventing or neutralizing every attempt at action. In my opinion, however, not all athletes have the ability to be in tune with the opponent, recognize an intention or action, and anticipate it in good time. I believe that this quality, in the evaluation of an athlete, should be considered in the same way as physical strength, flexibility, speed, and so on. Compared to strategy, emotions are also important aspects of a fight, so much so that we often try to induce them voluntarily. We think, for example, of the fairly typical custom of martial artists to "intimidate" the opponent in the initial stages of combat, causing controlled pain, or even before the fight, showing off one's abilities, speed, or particular techniques. All this obviously serves to induce a beneficial emotional state such as fear in the opponent.

\section{Participant no 3}

"Anticipate technique and emotion"

In the third interview, the interviewed athlete placed first at the Scottish Open Kyokushin Knockdown Championships of 2013 and 2014. The athlete expresses her opinions about emotional control and anticipation in the following answers:

1. Yes to all.

2. I would say that I agree with the study of Howell in 2003, as in training martial arts you are expected to branch out with your comfort zone in an effort to continuously improve yourself. While training, especially in preparation for a tournament, martial artists are pushed physically and mentally to ensure that they can have confidence in themselves when challenged against others, whether it is within kumite or kata. If one is not pushed to their physical and mental limits during training, there is a potential for them to become injured during kumite, as they may be unable to adequately defend and protect themselves. Pushing a karateka to their limits allows for continuous improvement.

3. I believe that highly trained martial artists mainly exhibit a higher level of emotional control. For example, during competition, those who are more inexperienced may have their performance affected by the pressure/nerves of competing and may be unable to retrieve themselves within kumite/kata if they have realized they have made a mistake or have points scored against them.

4. Yes, within training I have practiced combinations which aim to block different strikes and counterattack with an appropriate combination of strikes. Training and repetition of the combinations definitely does make an impact on the effectiveness of the technique, as I have been able to successfully complete combinations I have practiced for years. I believe that I am able to anticipate the movement of an individual prior to their attack not only through body movement, but also from watching exactly where they are looking at me. However, on a number of occasions I have sensed that my opponent may be injured/fatigued through their facial expressions and their body movements, which may be due to their emotions. I would agree that less experienced martial artists may not have the same ability as those who are better trained, as I believe these skills develop over the duration of training.

5. I believe it is extremely important to anticipate the technique and emotions of those who I am sparring with or competing against. Within the Dojo, it is important to anticipate emotion/technique to avoid injuring your training partner while sparring. During competition, anticipating your opponent's technique ensures that you can effectively block strikes and successfully counterattack, with the aim to avoid injury and win the fight. 


\section{Participant no 4}

"Managing the opponent's decision process"

The following answers were given by a $2^{\text {nd }}$ dan black belt kumite competitor, a two-time regional champion who placed third three times in the national championship and placed second in the international open championship. The athlete is also a mental coach.

1. Yes, I agree.

2. Stressful situations increase your attention, which is useful for improving both coping skills and control of emotions.

3. I can see a higher level of emotional control in martial arts athletes (for example, those who practice karate) both in kata and kumite. Emotions could increase internal dialogue, which is harmful during a competition. I consider empathy to be too close to emotions, so I think it could be as harmful as emotions during a competition. The only exception is for kata athletes: in fact, they must empathize with the warrior who fights against multiple opponents for his life in order to survive.

4. Yes, I practice those exercises to anticipate my opponent's attack, and yes, this type of training leads to improvement. Actually, I don't think that it's a matter of anticipation or feeling/reading emotions. Rather, what we do is manage the match by deciding when the opponent must attack. Once you can do this, you can anticipate your opponent's techniques because you decide when he has to attack. Generally, less experienced athletes cannot manage this skill properly.

5. As I said in the previous answers, there is an exception for kata athletes, but in general feeling the emotions of the adversary can be dangerous. In my opinion, it's not about feelings so much as it is about strategy. So, anticipating your opponent's technique is a core skill if you want to make a difference in the fight. In this case, it is also much more about managing the entire match instead of anticipating your opponent's techniques. Concerning "feeling the emotions of your opponent," this is, in my opinion, dangerous during a fight. You can try to intercept your opponent's feelings before the fight just to guess whether he's scared or not through his facial expressions, posture, and eye contact, but feeling the opponent's emotions (empathy) in the case of negative emotions or anxiety can be useless or dangerous.

\section{Results}

From the interviews, it can be understood that anticipating movement and feeling emotion is a great advantage in martial arts. The participants confirm, from their personal experience, that martial artists, in this case karate athletes, are subject to a high level of stress when training because of the continuous change of fighting situations and opponents that drives them to continuously research solutions, improving and challenging their coping skills. Coping is the process of managing demands (external or internal) that are appraised as taxing or exceeding the resources of the person (Andersson et al. 2003).

The first participant underlines that in his opinion, expert athletes don't aim to anticipate the opponent's technique or to understand what the opponent is feeling, but rather try to put the opponent in a situation that they know and want; this allows him to understand what the other is feeling and which technique he can choose. This is an "induced empathy," which is not easy to train and requires good control and mastery of both the body and emotions, while beginners focus much more on their own movements and feelings.

The second participant believes that the practice of martial arts is a powerful method for learning to control one's emotions and to understand the opponent empathetically. This participant considers empathy not only as the ability to understand what another person is feeling, but also the capacity to communicate and respond to others in an appropriate manner according to the received communicative stimuli. He thinks that the practice of exercise, which aims to anticipate the opponent's techniques, helps to build an unconscious database of movements that can be recognized when they occur and can thus be anticipated. This helps experts dominate the instinct and focus on the technique, but in beginners this occurs in the opposite manner. In the third interview, the subject gives an excellent example of what happens in a fight when you are able to bridge an emotional link with the opponent:

"I am able to anticipate the movement of an individual prior to their attack, not only by body movement, but also from watching exactly where they are looking at me. However, on a number 
of occasions I have sensed that my opponent may be injured/fatigued through their facial expressions and their body movements, which may be due to their emotions."

The fourth participant suggests that the stressing situation of the fight increases one's coping skills and emotional control. Controlling one's emotions and practicing empathy is necessary in martial arts to avoid an internal dialogue that can be dangerous during the fight.

The karate master thinks that it is more important to focus not on the anticipation of the movements but on managing the time when the opponent must attack, thus managing the correct responsive decisions.

\section{Discussion and Conclusions}

It is clear that working and training to anticipate movements and managing emotions is a core skill of martial artists. Training leads to improvement and forms the difference between beginners and athletes. The results show that martial artists are continuously focused on anticipating actions/situations related to the opponent and empathizing with the "enemy." Considering how mirror neurons show activity not only when a person moves, but also when a person observes someone else making that movement, this may be the result of a sort of automatic empathy of "really feeling what another person is feeling (Carey 2006). This research could be an inspiration and starting point for further physiological, neurological, or psychological studies to understand if the activity of mirror neurons is more developed in martial artists then others and if martial arts training affects the activity of mirror neurons.

\section{REFERENCES}

Andersson, G. \& Willebrand, M. (2003). What is coping? A critical review of the construct and its application in audiology. International Journal of Audiology, 42(Sup1), 97-103. doi: 10.3109/14992020309074630

Botvinick, M., Jha, A.P., Bylsma, L.M., Fabian, S.A., Solomon, P.E., \& Prkachin, K.M. (2005). Viewing facial expressions of pain engages cortical areas involved in the direct experience of pain. Retrieved May 2018 from PubMed database on the World Wide Web: https://www.ncbi.nlm.nih.gov/pubmed/15734365

Cheng, Y., Yang, C.Y., Lin, C.P., Lee, P.L., \& Decety, J. (2008). The perception of pain in others suppresses somatosensory oscillations: A magnetoencephalography study. Retrieved May 2018 from PubMed database on the World Wide Web:: https://www.ncbi.nlm.nih.gov/pubmed/18353686

Cook, R., Bird, G., Catmur, C., \& Press, C. (2014). From origin to function. Retrieved May 2018 from PubMed database on the World Wide Web: https://doi.org/10.1017/S0140525X13000903.

Dosil, J. (2006). The Sport Psychologist's Handbook: A Guide for Sport-Specific Performance Enhancement. Hoboken, NJ: John Wiley \& Sons Inc.

FIJLKAM. (2008). Regolamento d'arbitraggio per le competizioni di Karate. Retrieved May 2018, from: http://www.cusperugia.it/karate/modulistica/RegArbitraleKARATE_ediz2008.pdf

Gazzola, V., Aziz-Zadeh, L., \& Keysers, C. (2006). Empathy and the somatotopic auditory mirror system in humans. Current Biology, 16(18), 1824-1829. DOI: https://doi.org/10.1016/j.cub.2006.07.072

Goldberg, C. (2006). Empathy may begin at the neurons. Retrieved April 2018, from: https://www.nytimes.com/2006/01/10/health/empathy-may-begin-at-the-neurons.html

Heidelberg (2016). Reading an opponent's face gives the edge in martial arts. Springer. Retrieved May 2018, from: https://www.springer.com/gp/about-springer/media/research-news/all-english-research-news/reading-an-opponent-s-

face-gives-the-edge-in-martial-arts/10095184)

Howard, R. \& Croucher, M. (1983). The Way of the Warrior: The Paradox of the Martial Arts. New York, NY: Overlook Press.

Howell, L. (2003). Martial arts and confidence. Martial Artz UK. Retrieved April 2018, from: http://www.martialartz.co.uk/articles/article001.htm.

Iacoboni, M. (2009). Imitation, empathy, and mirror neurons. Annual Review of Psychology, 60, 653-70. doi: 10.1146/annurev.psych.60.110707.163604.

Ioannidou, F. \& Konstantikaki, V. (2008). Empathy and emotional intelligence: What is it really about. International Journal of Caring Sciences, 1(3), 118-123.

Jabbi, M., Swart, M., \& Keysers, C. (2007). Empathy for positive and negative emotions in the gustatory cortex. NeuroImage, 34(4), 1744-53. doi:10.1016/j.neuroimage.2006.10.032. PMID 17175173. 
Japan Fact Sheet. (2015). Martial arts. Web-Japan.org. Retrieved April 2018, from: http://webjapan.org/factsheet/en/pdf/e16_martial_art.pdf

Jimenez, L. (2017). Martial arts beyond a vision. Clinical and Experimental Psychology, 3, 165. doi: 10.4172/24712701.1000165.

Keysers, C. \& Gazzola, V. (2010). Social neuroscience: Mirror neurons recorded in humans. Current Biology, 8. Retrieved May 2018, from: https://doi.org/10.1016/j.cub.2010.03.013

Kim, H.-S. (2009). Taekwondo: A new strategy for Brand Korea. The Wayback Machine.

Kopel, D. (2017, January 11). The martial arts are arts. The Washington Post. Available at: https://www.washingtonpost.com/news/volokh-conspiracy/wp/2017/01/11/the-martial-arts-arearts/?utm term $=.9248 \mathrm{ef} 815537$

McCormick, L., Brumm, M.C., Beadle, J.N., Paradiso, S., Yamada, T., \& Andreasen, N. (2012). Mirror neuron function, psychosis, and empathy in schizophrenia. Psychiatry Research, 201(3), 233-9. doi:10.1016/j.pscychresns.2012.01.004. PMC 3545445. PMID 22510432

Molenberghs, P., Cunnington, R., \& Mattingley, J.B. (2009). Is the mirror neuron system involved in imitation? A short review and meta-analysis. Neuroscience and Biobehavioral Reviews, 33(7), 975-80. doi:10.1016/j.neubiorev.2009.03.010. PMID 19580913

Mukamel, R., Ekstrom, A.D., Kaplan, J., Iacoboni, M., \& Fried, I. (2010). Single-neuron responses in humans during execution and observation of actions. Current Biology, 20(8), 750-6. doi: 10.1016/j.cub.2010.02.045.

Richman, C.L. \& Rehberg, H. (1986). The development of self-esteem through the martial arts. International Journal of Sport Psychology, 17, 234-239.

Schneiderman, N., Ironson, G., \& Siegel, S.D. (2005). Stress and health: Psychological, behavioral, and biological determinants. Annual Review of Clinical Psychology, http://doi.org/10.1146/annurev.clinpsy.1.102803.144141

Shih, Y.L. \& Lin, C.Y. (2016). The relationship between action anticipation and emotion recognition in athletes of open skill sports. Retrieved May 2018 from PubMed database on the World Wide Web: https://www.ncbi.nlm.nih.gov/pubmed/27160338. DOI:10.1007/s10339-016-0764-7

Twemlow, S.W., Biggs, B.K., Nelson, T.D., Vernberg, E.M., Fonagy, P., \& Twemlow, S.W. (2008). Effects of participation in a martial arts-based antibullying program in elementary schools. Psychol. Schs., 45, 947-959.

Weinberg, R.S. \& Gould, D. (1999). Foundations of Sport and Exercise Psychology (2nd ed.). Champaign, IL: Human Kinetics.

AUTHOR'S ADDRESS: Danilo Contiero

Institute of Clinical Exercise and Health Science,

University of the West of Scotland

Almada St, Hamilton ML3 0JB, UK

E-mail: B00335320@studentmail.uws.ac.uk

Received: 12 March 2018; Accepted: 31 April 2018 